\title{
LOSS AVOIDANCE AS SELECTION PRINCIPLE: EVIDENCE FROM SIMPLE STAG-HUNT GAMES ${ }^{\dagger}$
}

\section{Ondrej Rydval, Andreas Ortmann*}

\author{
CERGE-EI
}

February 2004

\begin{abstract}
We investigate experimentally the conjecture by Cachon and Camerer (1996) that loss avoidance solves the tension that arises in stag-hunt games for which payoff dominance and risk dominance make conflicting predictions. Contrary to the conjecture, moneylosing outcomes do not shift behavior strongly toward the payoff-dominant equilibrium.
\end{abstract}

Keywords: Loss avoidance, Selection principle, Stag-hunt games, Coordination games, Experiment

JEL Classification: C72; C91; D91; D84

\footnotetext{
${ }^{\dagger}$ We thank Katarina Svitkova for research assistance, Petra Brhlikova, Eugen Kovac, Michal Ostatnicky, and Martin Vojtek for helping us run the experiments, and Sarka Hadravova (Czech Technical University, Prague), Jiri Hlavacek (Faculty of Social Sciences, Charles University, Prague), and Viatcheslav Vinogradov (CERGE-EI, Prague) for letting us conduct the experiments during their lectures, and Bank Austria for providing the funds. We thank ... for comments on earlier drafts.

* Corresponding author: Center for Economic Research and Graduate Education, Charles University, and Economics Institute, Academy of Sciences of the Czech Republic, Address: Politickych veznu 7, 11121 Prague, Czech Republic, Tel: +420-224-005-117, E-mail address: andreas.ortmann@cerge-ei.cz
} 


\section{Introduction}

Cachon and Camerer (1996) introduce loss avoidance, a selection principle that guides people to avoid strategies resulting in certain losses if offered other strategies with potential gains. The authors report that loss avoidance helped initiate coordination on better equilibria in their median effort game. This implies, they argue, that the range of payoffs - especially whether payoffs are gains or losses - may be an important feature of experimental design. As an example, they conjecture that in stag-hunt games where payoff dominance and risk dominance are in conflict, loss avoidance might reverse the previously reported gravitation toward the risk-dominant equilibrium (e.g., Cooper et al., 1992) in favor of the payoff-dominant equilibrium.

We conducted an experiment to investigate this conjecture. Participants chose either A or B in each of the five symmetric $2 \times 2$ stag-hunt games in Figure 1. ${ }^{1}$ Superimposed on the Experiment Sheet that was part of the instructions to the participants, we illustrate how Games 3-5 were derived from Game 2. Game 1, a control treatment where payoff and risk dominance pointed to the same equilibrium (A,C), offered participants a choice between a safe but relatively unattractive strategy B and a risky but relatively attractive strategy A. In the remaining four games, we moved the risk-dominant equilibrium ${ }^{2}$ to $(B, D)$ by increasing the relative attractiveness of the safe strategy B, although for Games

\footnotetext{
${ }^{1}$ A majority of participants in fact made choices for seven games. The two games not reported here ("intermediate" ones in terms of their payoffs) added no additional insights. The complete results are reported in Rydval and Ortmann (2004). Instructions are available at home.cergeei.cz/ortmann/instructions.html.

${ }^{2}$ Recall that a risk-dominant equilibrium has a greater Nash product of deviation losses (NPDL). In Game 2, for example, NPDL equals $(80-50) *(80-50)=900$ for the $(\mathrm{A}, \mathrm{C})$ equilibrium and (50$10)^{*}(50-10)=1600$ for the $(\mathrm{B}, \mathrm{D})$ equilibrium, the latter thus being risk-dominant.
} 
3 and 5 this strategy resulted in certain losses. Hence in these two games loss avoidance was assigned its intended role.

Figure 1: The Stag-hunt games and their connection (payoffs are in Czech Koruns)

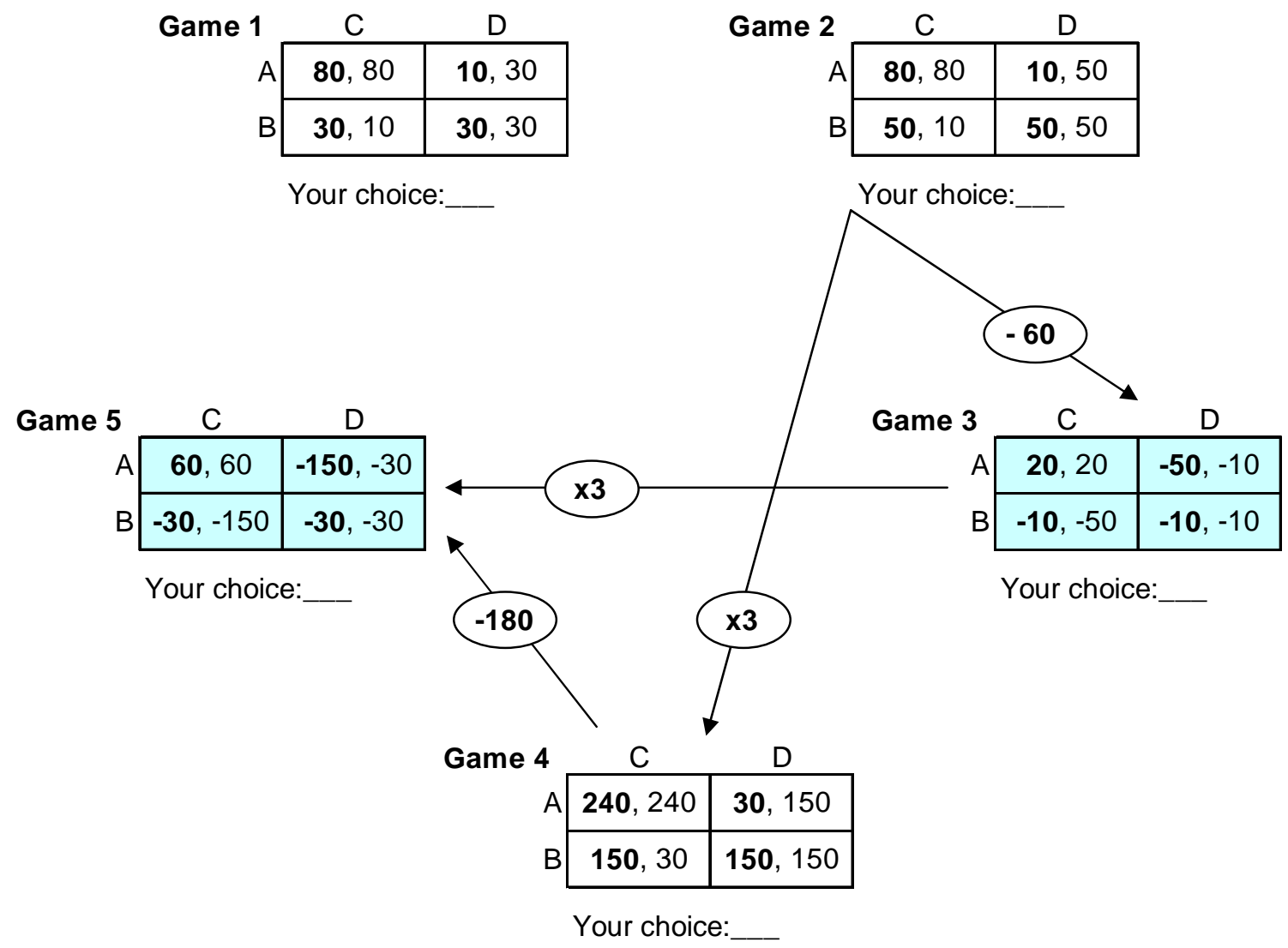

We entertained three hypotheses broadly formulated below as statistical alternatives to their respective null counterparts.

Hypothesis 1 (Risk dominance): Choice A is more likely in Game 1 than in Game 2.

Hypothesis 2 (Risk aversion): Choice A is more likely in Game 4 than in Game 2.

Hypothesis 3 (Loss Avoidance) : Choice A is more likely in Game 3 than in Game 2, and in Game 5 than in Game 4. 
The first two hypotheses were inspired by previously reported experimental results. Hypothesis 1 was a check on whether in Game 2, where unlike in Game 1 payoff dominance and risk dominance gave conflicting counsel, choice behavior indeed shifted toward the risk-dominant equilibrium (B,D). Hypothesis 2 was inspired by Holt and Laury (2002) whose subjects seemed more risk averse under higher stakes (though Harrison et al., 2003, argue persuasively that this was partly due to order effects). If risk aversion indeed increases with higher stakes, we would expect to observe more coordination on the payoff-dominant equilibrium $(\mathrm{A}, \mathrm{C})$ in Game 2 than in Game $4 .^{3}$

Hypothesis 3 examined whether, as conjectured by Cachon and Camerer, loss avoidance pushed participants toward the payoff-dominant equilibrium (B,D) in Games 3 and 5 relative to Games 2 and 4, respectively. Intuitively, loss avoidance told subjects to pick A to avoid the inevitable loss incurred when choosing $\mathrm{B}$, even at the expense of potentially incurring a higher loss. If loss avoidance were a salient selection principle, then subjects would assign low probability to such higher losses and choose accordingly.

We ran four sessions, the details of which are outlined in Table A in the Appendix. ${ }^{4}$ The sessions involved inexperienced subjects who had not taken game theory classes. We controlled for possible prominence of position by distributing various rotations of the

\footnotetext{
${ }^{3}$ For Game 3 and its scaled-up version Game 5, Hypothesis 2 is harder to test since loss avoidance might shift behavior toward the payoff-dominant equilibrium and thus confound the impact of risk aversion. This issue is pursued further in the Results section.

${ }^{4}$ We actually ran five sessions, but we excluded one from our analysis here because it was conducted with a small number of subjects who possessed game-theoretic background (some were even acquainted with the Cachon and Camerer (1996) paper) at the beginning of a brownbag seminar where we presented our results. We report the results for this session, as well as other implementation details, in Rydval and Ortmann (2004).
} 
games on the Experiment Sheet. ${ }^{5}$ Randomly selected pairs of participants (10-20\% in each session) earned the deserved payoffs for a game picked at random from their Experiment Sheet plus an initial endowment. Payoffs were in Czech Koruns except for Session 4 (Slovak Koruns), with exchange rate of around 30 Czech Koruns (35 Slovak Koruns) to $\$ 1$ and the purchasing power about twice that. All procedures were common knowledge.

As seen in Table A, the initial endowment was first reduced (with no systematic effects on our results), and then in Session 4 replaced by the "sudden death" treatment. This meant that selected participants who incurred a financial loss either had to pay up or faced the opportunity cost of being excluded from a follow-up experiment with sure nonnegative earnings. The goal of this treatment, inspired by a similar treatment in Abbink et al. (1999), was to establish higher credibility of the negative payoffs in Games 3 and 5 and thus increase the cutting power of loss avoidance.

\section{Results}

Looking first at aggregate-level data, Table 1 reports the percentages of A choices across all games and sessions (the two loss-avoidance games are shaded). Although Pearson's test suggested a certain degree of homogeneity across all sessions $(p=0.985)$, we treat them separately. As a preliminary insight revisited below, Sessions 1 and 3 invariably report higher frequencies of A choices than Sessions 2 and 4.

\footnotetext{
${ }^{5}$ Pearson's test for the homogeneity of populations suggested that we could safely pool data from all versions of the Experiment Sheet. We also tested for gender differences, obtaining highly insignificant results.
} 
Table 1: Frequencies and percentages of $A$ choices across games and sessions

\begin{tabular}{|l|c|c|c|c|c|}
\hline & Game 1 & Game 2 & Game 3 & Game 4 & Game 5 \\
\hline Session 1 & $80 \%$ & $57 \%$ & $66 \%$ & $57 \%$ & $59 \%$ \\
\hline Session 2 & $77 \%$ & $36 \%$ & $45 \%$ & $37 \%$ & $33 \%$ \\
\hline Session 3 & $85 \%$ & $56 \%$ & $71 \%$ & $50 \%$ & $56 \%$ \\
\hline Session 4 & $74 \%$ & $26 \%$ & $47 \%$ & $32 \%$ & $35 \%$ \\
\hline
\end{tabular}

Turning now to testing our three hypotheses in terms of the choice percentages, Hypothesis 1 found strong support in all sessions since Game 1 had a significantly higher percentage of A choices than Game 2 ( $p$-values for the $\mathrm{Z}$ statistics were below 0.01). Whereas around $80 \%$ of subjects attempted to coordinate on $(A, C)$ in Game 1 , the odds shifted in Game 2 by over 20 percentage points toward the risk-dominant equilibrium (B,D). The risk-aversion Hypothesis 2, in contrast, gained no statistical support at any conventional significance level: the increase in stakes between Games 2 and 4 did not induce subjects to shift towards the risk-dominant equilibrium (B,D). We show in Rydval and Ortmann (2004) that the choice behavior between these two games was rather noisy in all sessions, with $5-15 \%$ of subjects switching in either direction.

The loss-avoidance Hypothesis 3 gained statistically low support. Subjects did choose A more often in Game 3 than in Game 2, but only for Session 4 in a statistically significant manner $(p=0.04)$. The support was even weaker in the comparison of Games 4 and 5. As to the comparison of the loss-avoidance Games 3 and 5 where risk aversion and loss avoidance might give conflicting counsel, evidence was more supportive of the risk (or loss) aversion principle since subjects tended to choose B more often in Game 5 (the difference was significant only in Session 2 with $p=0.063$ ).

We now analyze our key Hypothesis 3 at a disaggregated level, focusing on Game 3 where it earlier found relatively stronger support. In Figure 2 are transition matrices for A 
and B choice percentages in Games 1, 2, and 3 that permit broadly separating subjects into "behavioral groups".

Figure 2: Transition matrices indicating percentages of subjects in each session

\begin{tabular}{|c|c|c|c|c|c|c|c|c|c|c|c|c|c|c|c|}
\hline \multirow{5}{*}{ 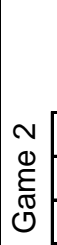 } & \multicolumn{3}{|c|}{$\underline{\text { Session } 1}$} & \multicolumn{4}{|c|}{ Session 2} & \multicolumn{4}{|c|}{ Session 3} & \multicolumn{4}{|c|}{ Session 4} \\
\hline & \multicolumn{3}{|c|}{ Game 3} & \multirow{4}{*}{ 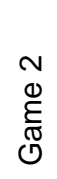 } & \multicolumn{3}{|c|}{ Game 3} & \multirow{4}{*}{$\begin{array}{c}\sim \\
\stackrel{1}{ } \\
\stackrel{్}{\mathbb{N}} \\
\mathbb{U}\end{array}$} & \multicolumn{3}{|c|}{ Game 3} & \multicolumn{4}{|c|}{ Game 3} \\
\hline & & $A$ & $B$ & & & $\bar{A}$ & $B$ & & & $A$ & $B$ & \multirow{3}{*}{$\begin{array}{l}N \\
\mathbb{D} \\
\stackrel{E}{\sigma} \\
\widetilde{N}\end{array}$} & & $\bar{A}$ & $B$ \\
\hline & $A$ & 50 & 7.1 & & $A$ & 24.7 & 11 & & $A$ & 47.1 & 8.8 & & $A$ & 20.6 & 5.9 \\
\hline & $B$ & 15.7 & 27.1 & & $B$ & 20.6 & 43.8 & & $B$ & 23.5 & 20.6 & & $B$ & 26.5 & 47 \\
\hline \multirow{6}{*}{ 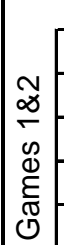 } & \multicolumn{3}{|c|}{ Game 3} & & \multicolumn{3}{|c|}{ Game 3} & \multirow{6}{*}{ 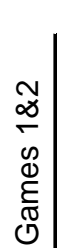 } & \multicolumn{3}{|c|}{ Game 3} & \multicolumn{4}{|c|}{ Game 3} \\
\hline & & $A$ & $B$ & \multirow{5}{*}{ 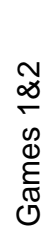 } & & $\bar{A}$ & $B$ & & & $A$ & $B$ & \multirow{5}{*}{ 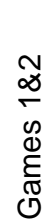 } & & $A$ & $B$ \\
\hline & $\overline{A A}$ & 47.1 & 2.9 & & $\overline{A A}$ & 24.7 & 8.2 & & $\overline{A A}$ & 47.1 & 8.8 & & $\overline{\mathrm{AA}}$ & 17.7 & 2.9 \\
\hline & $\mathrm{AB}$ & 12.9 & 17.1 & & $\mathrm{AB}$ & 13.7 & 30.1 & & $A B$ & 17.7 & 11.8 & & $A B$ & 20.6 & 32.4 \\
\hline & $\mathrm{BA}$ & 2.9 & 4.3 & & $\mathrm{BA}$ & 0 & 2.7 & & BA & 0 & 0 & & $\mathrm{BA}$ & 2.9 & 2.9 \\
\hline & BB & 2.9 & 10 & & BB & 6.9 & 13.7 & & BB & 5.9 & 8.8 & & BB & 5.9 & 14.7 \\
\hline
\end{tabular}

Note: All percentages are rounded to one decimal place, thus they may not add up to $100 \%$ in individual matrices. Also, the percentages in the bottom battery of transition matrices may not add up to those in the middle battery.

First inspect the top battery of transition matrices. Across sessions, only $15-27 \%$ of subjects chose B in Game 2 and A in Game 3, thus acting according to Hypothesis 3 (see shaded cells). From another angel, conditional on choosing B in Game 2, between one third to one half of subjects switched to A in Game 3. Note certain similarities between Sessions 1 and 3, namely their 50\% persistence of A-A choices, and Sessions 2 and 4 with a similarly high persistence of B-B choices. The number of "anomalous" (in terms of Hypothesis 3) A-B choices is relatively small in all sessions. Overall, persistence clearly dominates: A-A or B-B choices form $68-79 \%$ of all choices. (The persistence was confirmed by Pearson's tests showing a highly significant asymmetry for all four top transition matrices.)

Next inspect the bottom battery of extended transition matrices. The number of subjects choosing A-B-A in Games 1, 2, and 3 and thus acting according to Hypothesis 3 
conditional on Hypothesis 1 was only 13-21\% (see shaded cells). This was partly because it proved relatively unpopular, after choosing A-B in Games 1 and 2, to switch back to A in Game 3. Further, an absolute majority of subjects who chose A-A in Games 2 and 3 stuck to A also in Game 4. Confirming certain choice homogeneity, the modal choice behavior in Sessions 1 and 3 was A-A-A, whereas it was A-B-B in Sessions 2 and 4.

Complementary to the above analysis, we further examined whether choice behavior of the young talented mathematicians in Session 4 was related to their mathematical abilities. Such a relationship does not seem to be born out by evidence. Seven subjects satisfied Hypothesis 3 conditional on Hypothesis 1, but their mathematics scores varied widely from 73 to 133 . Further, of the 6 subjects with highest mathematics scores (above 120 out of 135), only one chose A-B-A whereas all others chose A-B-B, thus abiding with Hypothesis 1 but not with the loss-avoidance Hypothesis 3. Lastly, Pearson's test suggests that the average score did not significantly differ for those choosing A-A, A-B, B-A, and B-B, respectively, in Games 2 and 3.

\section{Discussion}

Our results pertaining to Hypothesis 1 confirm previously observed behavior in staghunt games featuring the conflict between payoff and risk dominance, namely the gravitation towards the risk-dominant equilibrium. This result suggests that there was nothing unusual about our subject pools. We did not observe increased preferences for the risk-dominant equilibrium when stakes were increased (Hypothesis 2). It is possible, and a topic of future research, that the stakes involved in Games 2 and 4 were too diluted and that we did not pay enough. The initial stakes in Holt and Laury (2002) were much higher to start with and were further increased by much more. Hence our results do not 
necessarily contradict theirs, and it would clearly be worthwhile to replicate our study with comparable payoffs.

The Cachon-Camerer conjecture (Hypothesis 3) that loss avoidance would help subjects coordinate on the payoff-dominant equilibrium in games with money-losing strategies received only moderate support in our data. Even though we observed some shift of choices in the predicted direction, less than a quarter of our subjects could legitimately be described as acting according to the loss avoidance selection principle. Persistence - i.e. holding on to either the payoff-dominant or the risk-dominant equilibrium - was the most frequently observed choice behavior.

The observed behavior did not seem to vary with mathematical ability or with subjects' background, though the apparent differences between results for Sessions 1 and 3 on the one hand and Sessions 2 and 4 on the other we cannot explain. ${ }^{6}$ As regards the implementation problem of establishing credibility of negative payoffs, we believe that the "sudden-death" treatment effectively solved this issue. However, we did not observe that the power of loss avoidance would be strengthened under the "sudden-death" treatment. Again this might be due to the somewhat diluted payoffs.

However, we are not ready yet to discard the loss-avoidance selection principle. Notice that the A-A choice in Games 2 and 3 could be as consistent with the CachonCamerer conjecture as the B-A choice we looked for. But having chosen A in Game 2, a subject had no way to switch to A in Game 3, no matter how much more (or less) she might have preferred it. The binary nature of the stag-hunt game thus makes it difficult to discern what proportion of our subjects really satisfied the Cachon-Camerer conjecture, and the above reported results may be too pessimistic. On the more optimistic side, 45-

\footnotetext{
${ }^{6}$ Systematic experimenter effects of the observed nature and scale seem unlikely.
} 
$70 \%$ of subjects in fact chose either A-A or B-A in Games 2 and 3, and similarly there were $40-65 \%$ of A-A-A and A-B-A choices in Games 1, 2, and 3 across all sessions.

In any case, possibly moderating the impact of loss avoidance in our games could have been its interaction with risk (or rather loss) aversion. That loss aversion played a role seems documented by the observed (though mostly insignificant) shift of choice behavior towards the risk-dominant equilibrium between the loss-avoidance Game 3 and its scaled-up version Game 5. Intuitively, the potential loss of $150 \mathrm{CZK}$ in Game 5 was substantial compared to $50 \mathrm{CZK}$ in Game 3, and this high negative payoff could have served as a deterrent to coordination.

In fact, this suggests a perception of risk other than that embedded in the NPDL formulation of risk dominance. Rather than their own deviations, players might worry about their opponent's choices. For instance, the row player choosing A in Game 5 risked losing 210 (in net) when the column player picked D instead of C, whereas choosing B was much less risky because she would have lost 30 regardless of the column player's choice. Related to this perception of risk, loss avoidance could have a smaller impact in our 2x2 stag-hunt games because they are minimum effort (i.e. "weakest link") games for which coordination is harder to achieve than in median-effort games (e.g., Goeree and Holt, 2001, and Blume and Ortmann, 2004). 


\section{APPENDIX}

Table A: Description of sessions (in the order they were run)

\begin{tabular}{|l||l|c|l|}
\hline & Subject Pool & $\begin{array}{l}\text { Instructions } \\
\text { language }\end{array}$ & Payment mode \\
\hline \hline Session 1 & $\begin{array}{l}70 \text { undergraduate students, } \\
\text { Czech Technical University, Prague }\end{array}$ & Czech & $\begin{array}{l}10 \text { subjects paid out (in CZK), } \\
200 C Z K \text { initial endowment }\end{array}$ \\
\hline Session 2 & $\begin{array}{l}73 \text { undergraduate students, } \\
\text { Fac. of Social Sciences, Charles U., Prague }\end{array}$ & Czech & $\begin{array}{l}10 \text { subjects paid out (in CZK), } \\
100 C Z K \text { initial endowment }\end{array}$ \\
\hline Session 3 & $\begin{array}{l}34 \text { graduate (first-year) students, } \\
\text { CERGE-El, Prague }\end{array}$ & English & $\begin{array}{l}6 \text { subjects paid out (in CZK), 100CZK } \\
\text { initial endowment }\end{array}$ \\
\hline Session 4 & $\begin{array}{l}34 \text { high-school pupils, } \\
\text { mathematics camp, Slovak Republic }\end{array}$ & Slovak & $\begin{array}{l}6 \text { subjects paid out (in SKK), no initial } \\
\text { endowment ("sudden death") }\end{array}$ \\
\hline
\end{tabular}




\section{REFERENCES}

Blume, A. and A. Ortmann, in prep, The effects of costless pre-play communication: experimental evidence from games with Pareto-ranked equilibria, Mimeo.

Cachon, G. P. and C. F. Camerer, 1996, Loss-avoidance and forward induction in experimental coordination games, Quarterly Journal of Economics 111, 165-194.

Cooper, R., R. DeJong, R. Forsythe and T. Ross, 1992, Communication in coordination games, Quarterly Journal of Economics 107, 739-71.

Goeree, J. K. and C. A. Holt, 2001, Ten little treasures of game theory and ten intuitive contradictions, American Economic Review 91, 1402-1422.

Harrison, G. W., E. Johnson, M. McInnes and E. E. Rutstrom, 2003, Risk aversion and incentive effects: comment, under review at American Economic Review.

Holt, C. A. and S. K. Laury, 2002, Risk aversion and incentive effects, American Economic Review 92, 1644-1655.

Rydval, O. and A. Ortmann, 2004, Loss avoidance as selection principle: evidence from simple stag-hunt games, CERGE-EI Discussion Paper. 